\title{
Residual patient, anatomic, and surgical obstacles in treating active left-sided infective endocarditis
}

\author{
Syed T. Hussain, MD, ${ }^{a}$ Nabin K. Shrestha, MD, ${ }^{b}$ Steven M. Gordon, MD, ${ }^{b}$ Penny L. Houghtaling, MS, \\ Eugene H. Blackstone, MD, ${ }^{\mathrm{a}, \mathrm{c}}$ and Gösta B. Pettersson, MD, PhD
}

Objectives: To identify and understand residual patient, anatomic, and surgical obstacles in treating active left-sided infective endocarditis (IE), we categorized the intraoperative pathologic entities in patients with left-sided IE and correlated the pathology (noninvasive vs invasive) and organism with IE context (affected valve, native vs prosthetic [PVE]) and surgical results.

Methods: From January 2002 to January 2011, 775 patients underwent surgery for active left-sided IE. Registries were queried, and endocarditis-related pathology was based on the echocardiographic findings and operative notes. Propensity adjustment and matching (55 pairs) were used for risk-adjusted outcome comparisons between the invasive aortic and mitral cases.

Results: A total of 395 patients had isolated aortic (PVE 59\%, invasive 68\%), 238 isolated mitral (PVE 29\%, invasive $35 \%$ ) , and 142 combined aortic and mitral (PVE 44\%, invasive $69 \%$ ) IE. The 30-day survival was $92 \%$ and was similar for native valve endocarditis and PVE in all 3 valve combinations. Invasive versus noninvasive IE was associated with greater hospital mortality $(11 \%$ vs $4.4 \%, P=.001)$. Patients with invasive IE had worse intermediate-term survival than those with noninvasive IE for mitral $(P=.001)$ and aortic plus mitral $(P=.02)$ IE but not for isolated aortic IE. This difference persisted in the matched patients.

Conclusions: During the past decade, we have had low hospital mortality for surgically treated left-sided IE and have neutralized the added risk of PVE. However, outcomes remain worse for mitral versus aortic valve IE, with residual obstacles related to patient factors, inherent mitral valve anatomy in patients with invasive disease, and lack of an alternative mitral valve prosthesis optimal for IE. (J Thorac Cardiovasc Surg 2014;148:981-8)

Supplemental material is available online.

The objectives of surgery for infective endocarditis (IE) are to debride and remove infected tissue and foreign material, prevent embolic events, and restore cardiac integrity and

\footnotetext{
From the Department of Thoracic and Cardiovascular Surgery, ${ }^{a}$ Heart and Vascular Institute, Department of Infectious Disease, ${ }^{\mathrm{b}}$ Medicine Institute, and Department of Quantitative Health Sciences, ${ }^{\mathrm{c}}$ Research Institute, Cleveland Clinic, Cleveland, Ohio.

This study was supported in part by the Peter and Elizabeth C. Tower and Family Endowed Chair in Cardiothoracic Research (G.B.P.), and by James and Sharon Kennedy, the Slosburg Family Charitable Trust, Stephen and Saundra Spencer, and Martin Nielsen. These individuals played no role in the collection of data or analysis and interpretation of the data and had no right to approve or disapprove publication of the finished report.

Disclosures: Steven M. Gordon reports consulting fees for 3M. Nabin K. Shrestha reports consulting fees for The Medicines Company and lecture fees for Merck and Forest. All other authors have nothing to disclose with regard to commercial support.

Read at the 94th Annual Meeting of The American Association for Thoracic Surgery, Toronto, Ontario, Canada, April 26-30, 2014.

Received for publication April 15, 2014; revisions received May 30, 2014; accepted for publication June 4, 2014; available ahead of print July 11, 2014.

Address for reprints: Gösta B. Pettersson, MD, PhD, Department of Thoracic and Cardiovascular Surgery, Cleveland Clinic, 9500 Euclid Ave, Desk J4-1, Cleveland, OH 44195 (E-mail: petterg@ ccf.org).

$0022-5223 / \$ 36.00$

Copyright $(2014$ by The American Association for Thoracic Surgery

http://dx.doi.org/10.1016/j.jtcvs.2014.06.019
}

functional valves. Despite the reduction of operative mortality and risk of subsequent prosthetic valve endocarditis (PVE) by a strategy that includes early radical surgery, the risks remain greater than those of operations for any other valve disease. ${ }^{1-6}$ These risks are related not only to the surgical challenges of treating IE but also to patient comorbidities and the local and systemic consequences of the IE: Local effects manifested by pathology stage related to the involved valve, and systemic effects by embolic events and dissemination and toxicity of the infection, both organism and time related. Traditionally, aortic and mitral valve endocarditis results are presented together or separately, and the outcomes have been related to general disease factors such as PVE, the presence of abscesses, or an aggressive organism. This has prevented the identification of both commonalities and contrasts of pathologic features and outcomes across the spectrum of left-sided IE.

Thus, the primary objectives of the present study were to identify and understand the residual patient, anatomic, and surgical obstacles to reducing the risk of surgical treatment of active left-sided IE. To accomplish this, we categorized the spectrum of intraoperative pathologic features in patients with active left-sided IE, correlated the pathology stage (noninvasive vs invasive IE) and organism with the IE context (affected valve, native valve endocarditis 


\section{Abbreviations and Acronyms \\ IE = infective endocarditis \\ $\mathrm{NVE}=$ native valve endocarditis \\ PVE $=$ prosthetic valve endocarditis}

[NVE] vs PVE) and surgical results, and compared the outcomes after accounting for patient morbidities.

\section{METHODS \\ Patients}

From January 1, 2002, to January 1, 2011, 963 left-sided IE cases were identified from the existing infectious disease and cardiac surgery registries, the medical records were reviewed, and the patients were classified using modified Duke criteria. ${ }^{7}$ Only cases meeting criteria for active aortic or mitral IE were included in the study ${ }^{1,8}$; healed and remote endocarditis (188 cases, $20 \%$ of left-sided IE) were excluded, leaving a study population of 775 cases. Of these, 395 patients $(51 \%)$ had isolated aortic valve IE, $238(31 \%)$ isolated mitral valve IE, and $142(18 \%)$ combined aortic and mitral valve IE. Patient characteristics, operative procedure details, and hospital outcomes were extracted from a prospective registry of all cardiac operations, and the microbiologic laboratory results and infectious disease serology were retrieved from the infectious disease registry. The Cleveland Clinic institutional review board approved the use of data extracted from all registries and a de novo review of the medical records for use in research, with patient consent waived.

\section{IE Characteristics}

The etiology of IE was determined by review of the microbiologic laboratory results and infectious disease serology. The surgical pathologic type was coded and stored in a Research Electronic Data Capture database, as previously described. ${ }^{8}$ Coding was determined from reviews of patient records, operative reports, and pre- and intraoperative transesophageal echocardiograms. IE was defined as noninvasive if it was confined to the cusps and leaflets and invasive if the infectious process extended beyond the cusp or leaflets into the annulus and surrounding structures. All pathologic findings were coded by the same surgeon (S.T.H.) retrospectively until 2008 and prospectively from January 2009 onward (in close collaboration with G.B.P.).

\section{IE Management}

At Cleveland Clinic, patients presenting with IE are treated by a multispecialty team. Surgery is advocated as soon as an indication has been established; we do not wait for heart failure to develop. However, many patients are already in heart failure when referred. All patients undergo brain imaging preoperatively to exclude hemorrhagic stroke. Having effective antibiotics on board at surgery is important, because we have seen persistent IE when this was not the case. When a patient is stable and without an elevated risk of embolic events, waiting for cultures and the sensitivity pattern may be justified. At surgery, radical debridement of all infected tissues and foreign material is followed by generous irrigation. Local antiseptics and antibiotics are used sparingly.

Allografts are preferred for aortic root reconstruction in patients with annulus destruction and invasive disease. When the annulus can be preserved, the choice of valve will not differ from that for other patients with valve disease. Mitral valve repair is preferred, and replacements are performed with chordal sparing when possible; autologous pericardium is the preferred material when needed for additional reconstructions. ${ }^{1}$

\section{Outcomes}

Postoperative complications were defined according to The Society of Thoracic Surgeons Adult Cardiac Surgery database (available at: http:// riskcalc.sts.org/STSWebRiskCalc273/About $\%$ 20the \%20STS \%20Risk \% 20Calculator\%20v2.73.pdf).
Follow-up of all patients who have undergone a heart valve operation is performed at 2 and 5 years and at 5-year intervals thereafter. This active follow-up protocol was supplemented with Social Security Death Master File information, ${ }^{9,10}$ with a closing date of April 27, 2011, 6 months after the query on October 27, 2011. A total of 2465 patient-years of follow-up data were available for analysis. Among the survivors, the median follow-up was 3.5 years, with $25 \%$ followed up $>6$ years and $10 \%>7.5$ years.

\section{Data Analysis}

Continuous variables are summarized as the mean \pm standard deviation or as the 15th, 50th (median), and 85th percentiles when the distribution was skewed. Comparisons were made using the Wilcoxon rank-sum test. Categorical data are summarized using frequencies and percentages. Comparisons were made using the chi-square test or Fisher's exact test when the frequency was $<5$. All analyses were performed using SAS statistical software, version 9.2 (SAS Institute, Inc, Cary, NC). Uncertainty is expressed by $68 \%$ confidence limits equivalent to \pm 1 standard error. In all analyses, repaired native valves were included in the NVE group.

Risk factors for mortality. Survival was studied overall, by affected valve, by NVE versus PVE, and by noninvasive versus invasive disease, overall and, again, by affected valve. Nonparametric survival estimates were obtained using the Kaplan-Meier method, and a parametric method was used to resolve the number of phases of an instantaneous risk of death (hazard function) and to estimate its shaping parameters. ${ }^{11}$ Thereafter, multivariable analyses were performed in the hazard function domain. Initially, separate models were developed for the aortic and mitral groups to uncover any possible interactions (varying effects of risk factors for each valve). Next, variable selection (Appendix E1 lists the candidate variables) was performed using bagging, with retention of variables with at least a $50 \%$ chance of $P<.05$. For this, stepwise regression was performed on 500 bootstrap data sets. Using the median rule, the variables that appeared in $\geq 50 \%$ of the bootstrap models were retained in the final model. $^{12,13}$

Risk adjustment using propensity method. Risk adjustment focused on invasive disease in the isolated aortic and isolated mitral valve IE groups. Initially, a parsimonious model was developed to understand the important differences between these 2 groups (Table E1). Multivariable logistic regression analysis was used with preoperative (only) candidate variables (Appendix E1). Variable selection used bagging and 1000 bootstrap samples, as described. Compared with invasive isolated aortic valve IE, invasive isolated mitral valve IE was associated with NVE, previous stroke, preoperative dialysis (acute or chronic), larger left atrial size, and female sex (Table E2).

Thereafter, we augmented the parsimonious model with 17 other variables representing preoperative patient demographic data, symptoms, and cardiac and noncardiac comorbidities that might be related to unrecorded selection factors (semisaturated model). A propensity score was calculated for each patient by solving the propensity model for the probability of being in the mitral valve IE group (compared with aortic). ${ }^{14}$ Next, using only the propensity score, patients with mitral IE were matched to patients with aortic IE using a greedy matching strategy. Patients whose propensity scores deviated $>0.15$ were considered unmatched. This yielded 55 well-matched patient pairs (Figure E1), $65 \%$ of the possible matches.

\section{RESULTS}

\section{Pathologic Characteristics}

Of the 775 patients, 395 had aortic valve IE, 238 had mitral valve IE, and 142 had combined aortic and mitral valve IE (Table E3); 362 (47\%) had PVE and 452 (58\%) had invasive IE (Table 1). Of the 395 patients with isolated aortic valve IE, $232(59 \%)$ had PVE and $270(68 \%)$ had 
TABLE 1. Clinical characteristics of patients with left-sided infective endocarditis treated surgically

\begin{tabular}{|c|c|c|c|c|c|c|}
\hline \multirow[b]{2}{*}{ Characteristic } & \multicolumn{3}{|c|}{ Infective endocarditis type } & \multicolumn{3}{|c|}{ Invasiveness } \\
\hline & $\operatorname{NVE}(n=413)$ & $\operatorname{PVE}(n=362)$ & $P$ value & $\begin{array}{c}\text { Noninvasive IE } \\
\quad(\mathbf{n}=\mathbf{3 2 3})\end{array}$ & $\begin{array}{c}\text { Invasive IE } \\
(n=452)\end{array}$ & $P$ value \\
\hline \multicolumn{7}{|l|}{ Demographic data } \\
\hline Age (y) & $55 \pm 14$ & $60 \pm 14$ & $<.0001$ & $55 \pm 14$ & $59 \pm 15$ & $<.0001$ \\
\hline Female sex & $139(34)$ & $91(25)$ & .012 & $111(35)$ & $121(27)$ & .02 \\
\hline \multicolumn{7}{|l|}{ Presentation } \\
\hline NYHA functional class III-IV & $132(32)$ & $99(27)$ & .16 & $106(33)$ & $125(28)$ & .12 \\
\hline Emergency or salvage & $22(5.3)$ & $20(5.6)$ & .9 & $14(4.4)$ & $27(6.0)$ & .4 \\
\hline Previous stroke & $142(34)$ & $126(35)$ & .8 & $120(37)$ & $147(33)$ & .16 \\
\hline Previous MI & $86(21)$ & $103 / 359(29)$ & .011 & 65/321 (20) & $124 / 451(27)$ & .02 \\
\hline Complete heart block or pacer & $18 / 408(4.4)$ & $45(13)$ & $<.0001$ & $12(3.8)$ & $51(11)$ & .0002 \\
\hline Acute or chronic renal disease requiring dialysis & $70(17)$ & $37 / 359(10)$ & .008 & $38 / 321(12)$ & 69/451 (15) & .17 \\
\hline Preoperative length of stay (d)* & $1.8,5.8,12$ & $1.9,5.9,13$ & .3 & $1.9,6.2,12$ & $1.8,5.4,12$ & .05 \\
\hline \multicolumn{7}{|l|}{ Cardiac morbidity } \\
\hline Previous cardiac operation & & & $<.0001$ & & & $<.0001$ \\
\hline None & $343(83)$ & $0(0)$ & & $202(63)$ & $147(33)$ & \\
\hline 1 & $65(16)$ & $238(66)$ & & $86(27)$ & $209(46)$ & \\
\hline 2 & $4(0.96)$ & $99(28)$ & & $27(8.4)$ & $76(17)$ & \\
\hline$\geq 3$ & $1(0.24)$ & $25(7.0)$ & & $6(1.8)$ & $20(4.5)$ & \\
\hline \multicolumn{7}{|l|}{ Aortic valve } \\
\hline Stenosis & $41(9.9)$ & $14(3.9)$ & .001 & $15(4.7)$ & $40(8.8)$ & .02 \\
\hline Regurgitation grade $3+/ 4+$ & $189(46)$ & $94(26)$ & $<.0001$ & $132(41)$ & $151(33)$ & .03 \\
\hline \multicolumn{7}{|l|}{ Mitral valve } \\
\hline Stenosis & $23(5.6)$ & $9(2.5)$ & .03 & $16(5.0)$ & $16(3.5)$ & .3 \\
\hline Regurgitation grade $3+/ 4+$ & $160(39)$ & $62(17)$ & $<.0001$ & $119(37)$ & $103(23)$ & $<.0001$ \\
\hline \multicolumn{7}{|l|}{ Noncardiac comorbidity } \\
\hline Hypertension & $254(62)$ & $254(70)$ & .009 & $195(61)$ & $313(69)$ & .01 \\
\hline Pharmacologically treated DM & 95/404 (24) & $77 / 352(22)$ & .6 & $58 / 315(18)$ & $114 / 441(26)$ & .02 \\
\hline COPD & $53(13)$ & $69(19)$ & .02 & $53 / 321(17)$ & $71 / 451(16)$ & .8 \\
\hline Peripheral arterial disease & $57(14)$ & $35(9.7)$ & .10 & $39 / 321(12)$ & $53 / 451(12)$ & .9 \\
\hline \multicolumn{7}{|l|}{ Operative details $\dagger$} \\
\hline AV repair & $17(4.1)$ & $3(0.83)$ & - & $16(5.0)$ & $4(0.88)$ & - \\
\hline \multicolumn{7}{|l|}{ AV replacement } \\
\hline Mechanical & $16(3.9)$ & $9(2.5)$ & - & $15(4.6)$ & $10(2.2)$ & - \\
\hline Xenograft & $101(24)$ & $38(11)$ & - & $90(28)$ & $49(11)$ & - \\
\hline Allograft & $111(27)$ & $246(68)$ & - & $52(16)$ & $305(67)$ & - \\
\hline MV repair & $141(34)$ & $50(14)$ & - & $94(29)$ & $97(21)$ & - \\
\hline \multicolumn{7}{|l|}{ MV replacement } \\
\hline Mechanical & $22(5.3)$ & $16(4.4)$ & - & $23(7.2)$ & $15(3.3)$ & - \\
\hline Xenograft & $114(28)$ & $96(27)$ & - & $99(31)$ & $111(25)$ & - \\
\hline CPB time (min) & $129 \pm 58$ & $184 \pm 68$ & $<.0001$ & $120 \pm 50$ & $179 \pm 69$ & $<.0001$ \\
\hline Aortic clamp time (min) & $103 \pm 48$ & $134 \pm 51$ & $<.0001$ & $91 \pm 39$ & $135 \pm 52$ & $<.0001$ \\
\hline
\end{tabular}

Data presented as mean \pm standard deviation or n (\%), unless otherwise noted. NYHA, New York Heart Association; MI, myocardial infarction; DM, diabetes mellitus; $C O P D$, chronic obstructive pulmonary disease; $A V$, aortic valve; $M V$, mitral valve; $C P B$, cardiopulmonary bypass; $I E$, infective endocarditis; $N V E$, native valve endocarditis; $P V E$, prosthetic valve endocarditis. *Data presented as 15 th, 50 th, 85 th percentiles. $\dagger$ Included procedures on noninfected valves.

invasive IE. Of the 238 with isolated mitral valve IE, 68 $(29 \%)$ had PVE $(P<.0001$ for the difference from aortic valve IE) and $84(35 \%)$ had invasive IE $(P<.0001$ for difference from aortic valve IE). Of the 142 with double valve IE, $11(7 \%)$ had PVE of 1 valve and NVE of the other, $25(18 \%)$ had PVE involving both valves, 77 (55\%) had NVE of both valves, and $3(2 \%)$ had 1 repaired native valve; 97 patients $(69 \%)$ had invasive disease.
For patients with invasive disease, the stage of invasiveness was cellulitis in $305(69 \%)$, abscess formation in $344(76 \%)$, an abscess cavity in $204(45 \%)$, and a pseudoaneurysm in $45(9.9 \%$; Table 2). Advanced invasiveness was more common in those with isolated aortic valve IE than in those with isolated mitral valve disease, just as was full-circumference IE. PVE was most often associated with invasive IE and NVE with noninvasive IE. 
TABLE 2. Valve pathology observed at surgery for left-sided infective endocarditis

\begin{tabular}{|c|c|c|c|c|c|}
\hline \multirow[b]{2}{*}{ Pathologic findings } & \multirow[b]{2}{*}{$\mathbf{A V}(\mathbf{n}=395)$} & \multirow[b]{2}{*}{$\operatorname{MV}(\mathbf{n}=\mathbf{2 3 8})$} & \multicolumn{3}{|c|}{$\mathbf{A V}+\mathbf{M V}(\mathbf{n}=\mathbf{1 4 2})$} \\
\hline & & & AV only & MV only & Both \\
\hline Vegetations & $329(83)$ & $224(94)$ & $11(7.8)$ & $15(11)$ & $111(78)$ \\
\hline Integrity abnormality of cusp or leaflet & $123(31)$ & $119(50)$ & $21(15)$ & $36(25)$ & $36(25)$ \\
\hline Invasive disease* & $270(68)$ & $84(35)$ & $54(38)$ & $7(4.9)$ & $37(26)$ \\
\hline \multicolumn{6}{|l|}{ Invasive disease stage*,$\dagger$} \\
\hline Cellulitis & $182(67)$ & $67(80)$ & 33 & 6 & 17 \\
\hline Abscess & $220(82)$ & $41(49)$ & 60 & 1 & 16 \\
\hline Abscess cavity & $126(46)$ & $20(24)$ & 38 & 3 & 14 \\
\hline Pseudoaneurysm & $32(12)$ & $1(1.2)$ & 4 & 2 & 0 \\
\hline \multicolumn{6}{|c|}{ Invasive disease extent (annular circumference) } \\
\hline$<1 / 3$ & $74(30)$ & $38(49)$ & 20 & 5 & 6 \\
\hline $1 / 3-1 / 2$ & $96(38)$ & $33(42)$ & 29 & 16 & 8 \\
\hline Full circumference & $80(32)$ & $7(9.0)$ & 16 & 0 & 2 \\
\hline
\end{tabular}

Data presented as n (\%). $A V$, Aortic valve; $M V$, mitral valve. *Percentage of invasive disease. $\dagger$ Invasive stage definitions as reported by Pettersson and colleagues.

The most common causative organisms were Staphylococcus aureus, coagulase-negative $S$ enterococcus, and Streptococcus viridans (Table 3). Staphylococcus species were most likely to be associated with invasive IE, streptococcus least likely, with the degree of invasiveness about equal for other organisms.

\section{Hospital Outcomes}

Hospital mortality was $8 \%$ overall, $7 \%$ for aortic valve IE, $6 \%$ for mitral valve IE, and $14 \%$ for combined aortic and mitral valve IE. Hospital mortality was higher $(10 \%)$ for those with PVE than for those with NVE $(6.3 \%$, $P=.04$; Table 4 ) and was $11 \%$ among patients with invasive IE versus $4.4 \%$ among those with noninvasive disease $(P<.0001)$. Renal failure was also more common after surgery for PVE and for invasive disease. Postoperative atrial fibrillation was less common after surgery for PVE. The use of an intra-aortic balloon pump was more common after surgery for aortic valve IE $(P=.005)$. Postoperative sepsis occurred in $10 \%$ of patients with mitral IE and $5.1 \%$ of those with aortic valve IE $(P=.02)$.

\section{Survival}

Overall unadjusted survival at 30 days, 6 months, and 1, 3,5 , and 7 years for these endocarditis patients was $92 \%$, $84 \%, 81 \%, 72 \%, 66 \%$, and $60 \%$, respectively. The hazard function resolved to 2 phases, with an early phase lasting about 6 months and accounting for about one half of the 245 deaths, and a late declining phase thereafter. Survival was higher for those with isolated aortic valve IE than for the mitral and combined groups $(73 \%$ at 5 years vs $60 \%$ and $51 \%$, respectively; $P<.0001$; Figure E2, $A$ ).

PVE versus NVE. Survival was similar after surgery for PVE or NVE $(67 \%$ vs $64 \%$ at 5 years; $P[\log$-rank $]=.6$; Figure E2, $B)$ and when stratified by valve $(P=.8$ after isolated aortic valve IE surgery, $P=.3$ after isolated mitral valve IE surgery, and $P=.4$ after combined aortic and mitral valve IE surgery; Figure 1).

Disease invasiveness. Survival was worse after surgery for invasive IE than after surgery for noninvasive disease, with a 5-year survival of $62 \%$ versus $70 \%$, respectively (Figure E2, C). However, when stratified by affected valve position, invasive mitral IE and invasive double valve IE

TABLE 3. Microbiologic etiology of infective endocarditis

\begin{tabular}{|c|c|c|c|c|c|c|c|c|c|}
\hline \multirow[b]{2}{*}{ Microorganism* } & \multicolumn{4}{|c|}{ Noninvasive $(n=323)$} & \multicolumn{4}{|c|}{ Invasive $(n=452)$} & \multirow{2}{*}{$\begin{array}{c}P \text { value } \\
\text { (invasive vs } \\
\text { noninvasive) }\end{array}$} \\
\hline & Overall & $\operatorname{NVE}(n=240)$ & PVE $(n=83)$ & $P$ value & Overall & $\operatorname{NVE}(n=173)$ & PVE $(n=279)$ & $P$ value & \\
\hline Staphylococcus aureus & $71(22)$ & $58(24)$ & $13(16)$ & .11 & $122(27)$ & $59(34)$ & $63(23)$ & .007 & .11 \\
\hline $\begin{array}{c}\text { Coagulase-negative } \\
\text { Staphylococcus }\end{array}$ & $40(12)$ & $25(10)$ & $15(18)$ & .07 & $99(22)$ & $24(14)$ & $75(27)$ & .0012 & .0007 \\
\hline Enterococcus & $42(13)$ & $33(14)$ & $9(11)$ & .5 & $51(11)$ & $21(12)$ & $30(11)$ & 6 & .5 \\
\hline Streptococcus viridans & $70(22)$ & $62(26)$ & $8(10)$ & .002 & $50(11)$ & $26(15)$ & $24(8.6)$ & .03 & $<.0001$ \\
\hline Gram-positive cocci $\dagger$ & $21(6.5)$ & $19(7.9)$ & $2(2.4)$ & .08 & $25(5.5)$ & $17(9.8)$ & $8(2.9)$ & .002 & 6 \\
\hline Fungal & $8(2.5)$ & $1(0.42)$ & $7(8.4)$ & $<.0001$ & $11(2.5)$ & $2(1.2)$ & $9(3.2)$ & .17 & $>.9$ \\
\hline Polymicrobial & $12(3.7)$ & $9(3.8)$ & $3(3.6)$ & $>.9$ & $12(2.7)$ & $6(3.5)$ & $6(2.2)$ & .4 & .4 \\
\hline Other & $23(7.1)$ & $11(4.6)$ & $12(15)$ & .003 & $46(10)$ & $11(6.4)$ & $35(13)$ & .03 & .14 \\
\hline Not identified & $36(11)$ & $22(9.2)$ & $14(17)$ & .05 & $36(8.0)$ & $7(4.1)$ & $29(10)$ & .02 & .13 \\
\hline
\end{tabular}

Data presented as n (\%). NVE, Native valve endocarditis; $P V E$, prosthetic valve endocarditis. *Final diagnosis. $\dagger$ Not identified further. 
TABLE 4. In-hospital complications after surgery for left-sided endocarditis

\begin{tabular}{|c|c|c|c|c|c|c|}
\hline Complication & $\operatorname{NVE}(n=413)$ & $\operatorname{PVE}(n=362)$ & $P$ value & Noninvasive $(\mathrm{n}=\mathbf{3 2 3})$ & Invasive $(n=452)$ & $P$ value \\
\hline In-hospital death & $26(6.3)$ & $37(10)$ & .04 & $14(4.4)$ & $49(11)$ & .001 \\
\hline Bleeding & $30(7.2)$ & $24(6.7)$ & .8 & $19(5.9)$ & $35(7.7)$ & .3 \\
\hline Stroke & $16(3.9)$ & $14(3.9)$ & .9 & $12(3.7)$ & $18(4)$ & .9 \\
\hline New renal failure requiring dialysis & $27(6.5)$ & $34(9.5)$ & .13 & $17(5.3)$ & $44(9.7)$ & .02 \\
\hline Renal failure & $55(13)$ & $80(22)$ & .001 & $41(13)$ & $94(21)$ & .004 \\
\hline Prolonged ventilation $(>24 \mathrm{~h})$ & $145(35)$ & $151(42)$ & .04 & $96(30)$ & $200(44)$ & $<.0001$ \\
\hline Sepsis & $36(8.7)$ & $34(9.5)$ & .13 & $21(6.5)$ & $49(11)$ & .04 \\
\hline Atrial fibrillation & $110(29)$ & $50(16)$ & $<.0001$ & $71(24)$ & $89(22)$ & .4 \\
\hline Use of IABP & $12(2.9)$ & $18(5.0)$ & .13 & $7(2.2)$ & $23(5.1)$ & .04 \\
\hline \multicolumn{7}{|l|}{ Length of stay* } \\
\hline ICU (h) & $25,74,335$ & $27,102,327$ & .02 & $25,67,282$ & $28,114,357$ & $<.0001$ \\
\hline Postoperative (d) & $6.2,12,22$ & $6.8,12,26$ & .2 & $6.1,10,23$ & $7.0,13,24$ & .002 \\
\hline Hospital (d) & $10,19,36$ & $11,19,36$ & .2 & $10,18,34$ & $11,19,37$ & .2 \\
\hline
\end{tabular}

Data presented as n (\%), unless otherwise noted. $N V E$, Native valve endocarditis; $P V E$, prosthetic valve endocarditis; $I A B P$, intra-aortic balloon pumping; $I C U$, intensive care unit. *Data presented as 15 th, 50 th, 85 th percentiles.

were associated with worse survival, but invasive and noninvasive aortic valve IE as well as noninvasive mitral valve IE and noninvasive double valve disease were all associated with similar and better survival than were invasive mitral and invasive double valve IE (Figure 2).

Risk-adjusted mortality. Invasive IE involving the mitral valve was associated with much worse survival than invasive aortic valve disease $(46 \%$ vs $74 \%$ at 5 years, respectively; $P<.0001$; Figure E3, A). Although the risk estimates stayed the same, this was not the case for the propensity-matched patients $(55 \%$ vs $73 \%$ at 5 years; $P=.4$, Figure E3, $B)$. This resulted from differences in the risk factors for early mortality, such as elevated bilirubin and blood urea nitrogen, peripheral arterial disease, and older age, as well as differences in risk factors for late

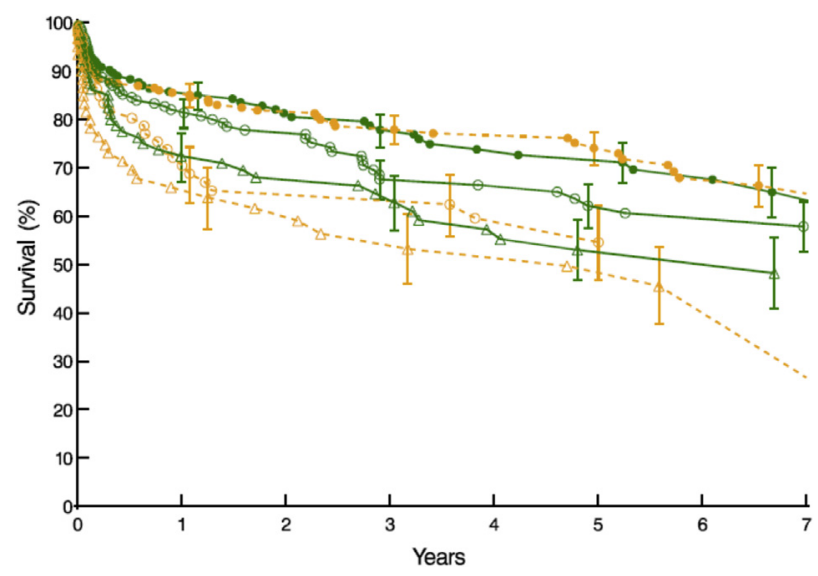

FIGURE 1. Survival after surgery for native or prosthetic valve left-sided valve infective endocarditis (IE). Each symbol represents a death, and vertical bars represent the $68 \%$ confidence limits, equivalent to \pm 1 standard error. Solid green lines indicate native valve endocarditis; dashed orange lines, prosthetic valve endocarditis; filled circles, aortic valve IE alone; open circles, mitral valve IE alone; and triangles, aortic and mitral valve IE. survival, including older age and chronic obstructive pulmonary disease (Table E2). Thus, unmatched patients with invasive mitral valve disease had particularly poor survival (Figure 3).

\section{DISCUSSION}

As a paradoxical effect of advances in medical and surgical therapy, the incidence of IE has increased during the past 30 years. ${ }^{15-19}$ People live longer, undergo procedures with the potential for bacteremia, and an increasing number undergo heart surgery or receive prosthetic valves, pacemakers, and defibrillators, all factors associated with an increased risk of IE.

To our knowledge, our report represents the first endocarditis study in which pathologic type has been systematically coded and staged, as described in an earlier

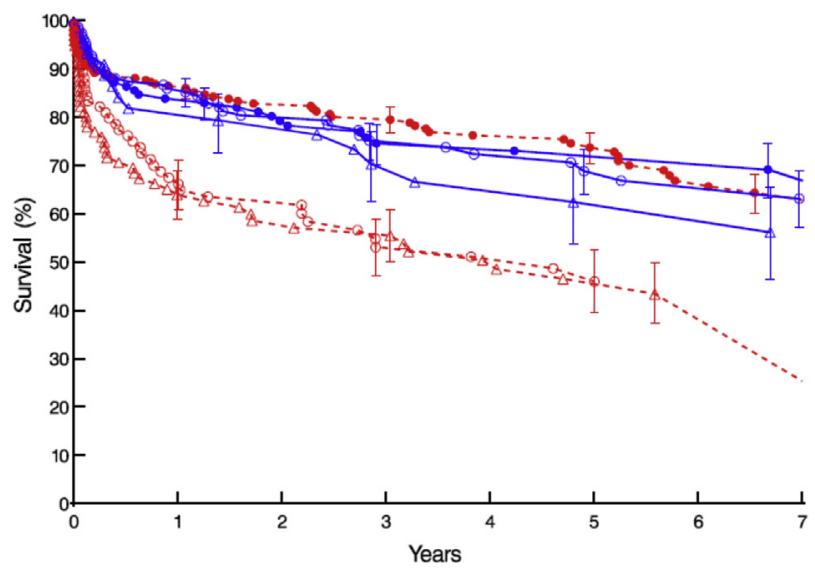

FIGURE 2. Survival after surgery for invasive versus noninvasive left-sided infective endocarditis according to valve position. Solid blue lines indicate noninvasive infective endocarditis; and dashed red lines, invasive infective endocarditis. Each symbol represents a death, and vertical bars represent the $68 \%$ confidence limits, equivalent to \pm 1 standard error. 


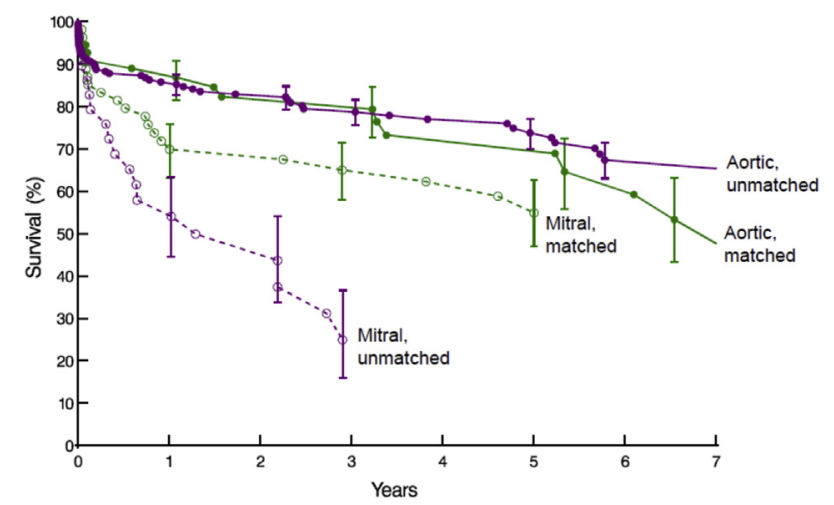

FIGURE 3. Survival after surgery for invasive infective endocarditis for propensity-matched and unmatched isolated aortic and mitral valve cases. Each symbol represents a death, and vertical bars represent the $68 \%$ confidence limits, equivalent to \pm 1 standard error.

publication, ${ }^{8}$ with outcomes analyzed by disease invasiveness and stage. The present study also reports a contemporary surgical experience with IE at a surgically aggressive tertiary center operating on $>100$ patients with IE annually.

Traditionally, the general disease factors associated with worse outcomes after surgery for left-sided IE have been PVE, the presence of an abscess, and an aggressive organism ( $S$ aureus). In the present study, we focused, not only on these factors, but also on a direct comparison of aortic and mitral IE. This revealed several new observations of differences between them. There were almost twice as many aortic cases as mitral cases, the aortic cases had a much higher percentage of PVE, and the aortic disease was correspondingly more invasive. The characteristics of the patient population affected by mitral valve IE were very different from those of patients with aortic valve IE, with the mitral patients at greater risk (Figure E1, B). Although overall mortality was $8 \%$, better than we have reported previously, it was still higher than that for any other surgical valve disease. ${ }^{15-18}$ Both mortality and survival were worse for mitral IE than for aortic IE and even worse for combined aortic and mitral IE. The characteristics and behavior of concomitant mitral and aortic valve IE were more like those of mitral valve disease. Similar outcomes for mitral IE have been reported previously. 6,20

In our present study, PVE, although associated with greater hospital mortality, was not associated with worse survival than NVE in any group, although the PVE patients were older and had more comorbidities. This is in contrast to previous reports. For example, David and colleagues ${ }^{4}$ reported much worse long-term survival for patients with PVE than for those with NVE. Leontyev and colleagues ${ }^{21}$ reported hospital mortality of $24 \%$ and 5 -year survival of $37 \%$ in 152 PVE patients in a recent series. Worse outcomes in PVE patients have been reported by several others. ${ }^{22-28}$
In contrast, in our study, the patients with invasive disease had distinctly worse overall outcome, mortality, and survival than those with noninvasive disease. However, when analyzed by affected valve, this was true only for invasive mitral valve IE. Although the statistical significance disappeared after propensity matching, the risk estimate remained the same. This is in agreement with our perception that we have learned to master invasive aortic IE but not invasive mitral IE. We debride the aortic root extensively without fear because we trust that reconstruction with an allograft will be easy and straightforward and produce excellent results. In contrast, mitral valve IE is invasive to the atrioventricular groove, and radical debridement, sterilization, and drainage of the infected area are much more difficult. One concern is that debridement is less controlled and suboptimal when invasion into the atrioventricular groove is deep. In addition, no replacement alternative is available for the mitral valve that is equally simple to implant and as good as the allograft is for the aortic valve; allograft mitral valve replacement is not simple and is still experimental. ${ }^{29}$ Fortunately, a lower percentage of mitral valve IE is invasive, and when invasive, few cases are deep and extensive. In the published data, it is also well recognized that IE with an annular or a periannular abscess is associated with a worse prognosis, and operative mortalities as high as $31 \%$ have been reported. Differences among studies are related to multiple factors, with the experience of the surgical team an important one. ${ }^{1-6,22,30,31}$ However, these studies combine aortic and mitral IE and do not separate them. Also, in the published studies, it is difficult to distinguish between invasive disease and PVE. For 135 patients with a paravalvular abscess treated surgically, David and colleagues ${ }^{5}$ reported a mortality stratified by the involved valve of $10.9 \%, 11.1 \%$, and $30 \%$, respectively, for aortic, mitral, and combined aortic and mitral endocarditis and by NVE versus PVE of $11.6 \%$ and $19.7 \%$, respectively.

Although the role of surgery in active IE has expanded, the indications and timing of surgery are still debated. ${ }^{32-36}$ With increasing experience, surgical mortality for active IE has decreased considerably, ${ }^{1}$ and surgeons have become increasingly aggressive. We have all learned and accepted the basic principles for how to manage such disease operatively: Radical debridement of all infected tissues, generous irrigation, use of allografts for aortic root replacement when the aortic annulus is involved, use of autologous pericardium when additional tissue is needed, and avoidance of foreign material, prosthetic grafts, and glue. ${ }^{1-3}$ The surgical results will depend on many variables, including patient characteristics, timing of surgery, ${ }^{32-36}$ whether an emergency procedure is required, ${ }^{30,37}$ virulence of the organism, ${ }^{1,36,38}$ whether the affected valve is native or prosthetic, and whether the 
infection has extended into the valve annulus and surrounding tissues, causing abscesses, fistulas, and pseudoaneurysms with an increased risk of adverse outcomes, including death. Although some organisms, such as $S$ aureus, are more aggressive and invasive than others, most will eventually be invasive and destructive, given enough time. That the pathologic stage is more important than whether it is NVE or PVE suggests that we should operate earlier to avoid allowing the infection to become more invasive.

\section{Strengths and Limitations}

The present study was a contemporary, but retrospective, study from a busy tertiary referral center with long-standing interest in the surgical treatment of endocarditis. Coding of the pathologic entity was based on all available information and was done by a single surgeon, not the operating surgeon in most cases. Survival bias has been brought up as a factor unfairly favoring surgery ${ }^{39}$; however, we can operate only on patients who are still alive and operable when we first see them.

\section{CONCLUSIONS}

Hospital mortality for surgically treated left-sided IE has decreased, and the added risk of PVE has been neutralized. We attribute this to our aggressive team approach and treatment strategies, including early surgery. However, the outcomes are still worse for mitral valve IE. The residual obstacles are related to the patient, the inherent mitral valve anatomy in patients with invasive disease, and the lack of an alternative mitral valve prosthesis optimal for IE.

\section{References}

1. Manne MB, Shrestha NK, Lytle BW, Nowicki ER, Blackstone E, Gordon SM, et al. Outcomes after surgical treatment of native and prosthetic valve infective endocarditis. Ann Thorac Surg. 2012;93:489-93.

2. Sabik JF, Lytle BW, Blackstone EH, Marullo AG, Pettersson GB, Cosgrove DM. Aortic root replacement with cryopreserved allograft for prosthetic valve endocarditis. Ann Thorac Surg. 2002;74:650-9; discussion 9.

3. Lytle BW, Sabik JF, Blackstone EH, Svensson LG, Pettersson GB, Cosgrove DM III. Reoperative cryopreserved root and ascending aorta replacement for acute aortic prosthetic valve endocarditis. Ann Thorac Surg. 2002:74:S1754-7; discussion S92-9.

4. David TE, Gavra G, Feindel CM, Regesta T, Armstrong S, Maganti MD. Surgical treatment of active infective endocarditis: a continued challenge. J Thorac Cardiovasc Surg. 2007;133:144-9.

5. David TE, Regesta T, Gavra G, Armstrong S, Maganti MD. Surgical treatment of paravalvular abscess: long-term results. Eur J Cardiothorac Surg. 2007;31: 43-8.

6. Sheikh AM, Elhenawy AM, Maganti M, Armstrong S, David TE, Feindel CM. Outcomes of surgical intervention for isolated active mitral valve endocarditis. J Thorac Cardiovasc Surg. 2009;137:110-6.

7. Li JS, Sexton DJ, Mick N, Nettles R, Fowler VG Jr, Ryan T, et al. Proposed modifications to the Duke criteria for the diagnosis of infective endocarditis. Clin Infect Dis. 2000;30:633-8.

8. Pettersson GB, Hussain ST, Shrestha NK, Gordon S, Fraser TG, Ibrahim KS, et al. Infective endocarditis: an atlas of disease progression for describing, staging, coding, and understanding the pathology. J Thorac Cardiovasc Surg. 2014;147:1142-9.e2.

9. Boyle CA, Decoufle P. National sources of vital status information: extent of coverage and possible selectivity in reporting. Am J Epidemiol. 1990;131:160-8.
10. Newman TB, Brown AN. Use of commercial record linkage software and vital statistics to identify patient deaths. J Am Med Inform Assoc. 1997;4: 233-7.

11. Blackstone EH, Naftel DC, Turner ME Jr. The decomposition of time-varying hazard into phases, each incorporating a separate stream of concomitant information. J Am Stat Assoc. 1986;81:615-24.

12. Breiman L. Bagging predictors. Machine Learning. 1996;24:123-40.

13. Sauerbrei W, Schumacher M. A bootstrap resampling procedure for model building: application to the Cox regression model. Stat Med. 1992;11: 2093-109.

14. Rubin DB. The design versus the analysis of observational studies for causal effects: parallels with the design of randomized trials. Stat Med. 2007; 26:20-36.

15. Cabell CH, Abrutyn E, Fowler VG Jr, Hoen B, Miro JM, Corey GR, et al. Use of surgery in patients with native valve infective endocarditis: results from the International Collaboration on Endocarditis Merged Database. Am Heart J. 2005; 150:1092-8.

16. Murdoch DR, Corey GR, Hoen B, Miro JM, Fowler VG Jr, Bayer AS, et al. Clinical presentation, etiology, and outcome of infective endocarditis in the 21st century: the International Collaboration on Endocarditis-Prospective Cohort Study. Arch Intern Med. 2009;169:463-73.

17. Hoen B, Duval X. Clinical practice. Infective endocarditis. N Engl J Med. 2013; 368:1425-33.

18. Bashore TM, Cabell C, Fowler V Jr. Update on infective endocarditis. Curr Probl Cardiol. 2006;31:274-352.

19. Galvez-Acebal J, Rodriguez-Bano J, Martinez-Marcos FJ, Reguera JM, Plata A, Ruiz J, et al. Prognostic factors in left-sided endocarditis: results from the Andalusian multicenter cohort. BMC Infect Dis. 2010;10:17.

20. Greason KL, Thomas M, Steckelberg JM, Daly RC, Schaff HV, Li Z, et al Outcomes of surgery in the treatment of isolated nonnative mitral valve infective endocarditis. J Thorac Cardiovasc Surg. 2014;147:349-54.

21. Leontyev S, Borger MA, Modi P, Lehmann S, Seeburger J, Walther T, et al Redo aortic valve surgery: influence of prosthetic valve endocarditis on outcomes. J Thorac Cardiovasc Surg. 2011;142:99-105.

22. Leontyev S, Borger MA, Modi P, Lehmann S, Seeburger J, Doenst T, et al Surgical management of aortic root abscess: a 13-year experience in 172 patients with 100\% follow-up. J Thorac Cardiovasc Surg. 2012;143:332-7.

23. Musci M, Weng Y, Hubler M, Amiri A, Pasic M, Kosky S, et al. Homograft aortic root replacement in native or prosthetic active infective endocarditis: twenty-year single-center experience. J Thorac Cardiovasc Surg. 2010;139:665-73.

24. Wang A, Athan E, Pappas PA, Fowler VG Jr, Olaison L, Pare C, et al Contemporary clinical profile and outcome of prosthetic valve endocarditis JAMA. 2007;297:1354-61.

25. Edwards MB, Ratnatunga CP, Dore CJ, Taylor KM. Thirty-day mortality and long-term survival following surgery for prosthetic endocarditis: a study from the UK heart valve registry. Eur J Cardiothorac Surg. 1998;14:156-64.

26. Alonso-Valle H, Farinas-Alvarez C, Garcia-Palomo JD, Bernal JM, Martin-Duran R, Gutierrez Diez JF, et al. Clinical course and predictors of death in prosthetic valve endocarditis over a 20-year period. J Thorac Cardiovasc Surg. 2010;139:887-93.

27. Wang A, Pappas P, Anstrom KJ, Abrutyn E, Fowler VG Jr, Hoen B, et al. The use and effect of surgical therapy for prosthetic valve infective endocarditis: a propensity analysis of a multicenter, international cohort. Am Heart J. 2005; 150:1086-91.

28. Romano G, Carozza A, Della Corte A, De Santo LS, Amarelli C, Torella M, et al. Native versus primary prosthetic valve endocarditis: comparison of clinical features and long-term outcome in 353 patients. J Heart Valve Dis. 2004;13: 200-8; discussion 8-9.

29. Navia JL, Al-Ruzzeh S, Gordon S, Fraser T, Aguero O, Rodriguez L. The incorporated aortomitral homograft: a new surgical option for double valve endocarditis. J Thorac Cardiovasc Surg. 2010;139:1077-81.

30. Yankah AC, Pasic M, Klose H, Siniawski H, Weng Y, Hetzer R. Homograft reconstruction of the aortic root for endocarditis with periannular abscess: a 17-year study. Eur J Cardiothorac Surg. 2005;28:69-75.

31. Anguera I, Miro JM, Cabell CH, Abrutyn E, Fowler VG Jr, Hoen B, et al. Clinical characteristics and outcome of aortic endocarditis with periannular abscess in the International Collaboration on Endocarditis Merged Database. Am J Cardiol. 2005;96:976-81.

32. Kang DH, Kim YJ, Kim SH, Sun BJ, Kim DH, Yun SC, et al. Early surgery versus conventional treatment for infective endocarditis. N Engl J Med. 2012;366: 2466-73. 
33. Gordon SM, Pettersson GB. Native-valve infective endocarditis-when does it require surgery? N Engl J Med. 2012;366:2519-21.

34. Thuny F, Grisoli D, Collart F, Habib G, Raoult D. Management of infective endocarditis: challenges and perspectives. Lancet. 2012;379: 965-75.

35. Thuny F, Habib G. When should we operate on patients with acute infective endocarditis? Heart. 2010;96:892-7.

36. Ohara T, Nakatani S, Kokubo Y, Yamamoto H, Mitsutake K, Hanai S. Clinical predictors of in-hospital death and early surgery for infective endocarditis: results of CArdiac Disease REgistration (CADRE), a nation-wide survey in Japan. Int J Cardiol. 2013;167:2688-94.
37. Gelsomino S, Maessen JG, van der Veen F, Livi U, Renzulli A, Luca F, et al Emergency surgery for native mitral valve endocarditis: the impact of septic and cardiogenic shock. Ann Thorac Surg. 2012;93:1469-76.

38. Miro JM, Anguera I, Cabell CH, Chen AY, Stafford JA, Corey GR, et al. Staphylococcus aureus native valve infective endocarditis: report of 566 episodes from the International Collaboration on Endocarditis Merged Database. Clin Infect Dis. 2005;41:507-14.

39. Tleyjeh IM, Kashour T, Zimmerman V, Steckelberg JM, Wilson WR, Baddour LM. The role of valve surgery in infective endocarditis management: a systematic review of observational studies that included propensity score analysis. Am Heart J. 2008;156:901-9. 


\section{APPENDIX E1. VARIABLES CONSIDERED IN MULTIVARIABLE ANALYSES \\ Demographic Data}

Age (years), sex, race (black, white, other), height $(\mathrm{cm})$, weight $(\mathrm{kg})$, body surface area $\left(\mathrm{m}^{2}\right)$, body mass index $\left(\mathrm{kg} / \mathrm{m}^{2}\right)$

\section{Presentation}

New York Heart Association functional class (I-IV), emergency or salvage operation, complete heart block, previous stroke, previous myocardial infarction

\section{Cardiac Comorbidity}

Preoperative atrial fibrillation, systolic blood pressure $(\mathrm{mm} \mathrm{Hg})$, diastolic blood pressure $(\mathrm{mm} \mathrm{Hg})$, number of previous cardiac operations, heart failure

\section{Noncardiac Comorbidity}

Pharmacologically treated diabetes (insulin and noninsulin dependent), hypertension, peripheral arterial disease, history of smoking, chronic obstructive pulmonary disease, renal failure requiring dialysis, blood urea nitrogen $(\mathrm{mg} / \mathrm{dL})$, creatinine $(\mathrm{mg} / \mathrm{dL})$, bilirubin $(\mathrm{mg} / \mathrm{dL})$, cholesterol $(\mathrm{mg} / \mathrm{dL})$ (total, high-density lipoprotein, low-density lipoprotein), triglycerides $(\mathrm{mg} / \mathrm{dL})$, hematocrit $(\%)$

\section{Preoperative Echocardiographic Data}

Aortic valve regurgitation grade, mitral valve regurgitation grade, tricuspid valve regurgitation grade, aortic valve stenosis, mitral valve stenosis, left ventricular (LV) ejection fraction $(\%), \mathrm{LV}$ internal diastolic diameter $(\mathrm{cm}), \mathrm{LV}$ internal systolic diameter $(\mathrm{cm}), \mathrm{LV}$ end-diastolic volume $(\mathrm{mL}), \mathrm{LV}$ end-systolic volume $(\mathrm{mL}), \mathrm{LV}$ mass $(\mathrm{g})$, left atrial diameter $(\mathrm{cm})$, left atrial volume $(\mathrm{mL})$

\section{Procedural}

Type of aortic or mitral valve surgery (repair; replacement with mechanical valve, xenograft, or allograft; native or prosthetic), concomitant tricuspid valve surgery, coronary artery bypass grafting, use of internal thoracic artery, incision (full sternotomy or less invasive), cardiopulmonary bypass time (min), aortic clamp time (min), surgeon

\section{Endocarditis Details}

Prosthetic or native valve, invasive disease, microorganism pathology, Duke criteria

\section{Experience}

Date of operation (days from January 1, 2002, to surgery) 

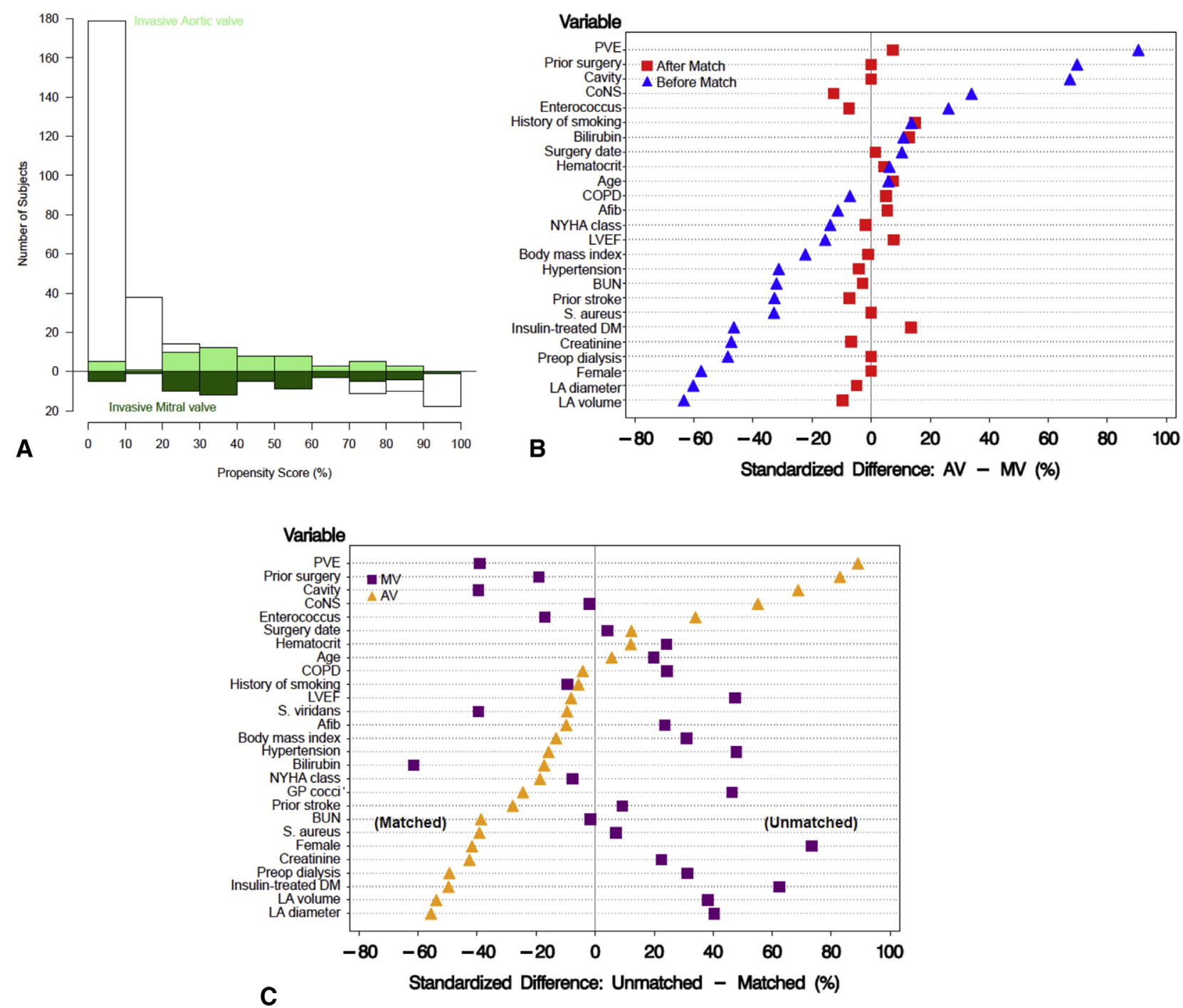

FIGURE E1. Results of propensity matching for various isolated invasive mitral valve infective endocarditis and isolated invasive aortic valve disease. A, Mirrored histogram of propensity score distribution. Darkened bars represent matched patients. B, Covariable balance before and after matching. Values on the horizontal axis represent the percentage standardized difference* between mitral valve and aortic valve IE groups. C, Standardized differences* between matched and unmatched cases. $P V E$, prosthetic valve endocarditis; CoNS, coagulase-negative staphylococci; $C O P D$, chronic obstructive pulmonary disease; $L V E F$, left ventricular ejection fraction; Afib, atrial fibrillation; NYHA, New York Heart Association; GP, gram-positive; BUN, blood urea nitrogen; Preop, preoperative; $D M$, diabetes mellitus; $L A$, left atrial; $A V$, aortic valve; $M V$, mitral valve. *Austin PC, Mamdani MM. A comparison of propensity score methods; a case study estimating the effectiveness of post-MI statin use. Stat Med. 2006;25:2084-106. 

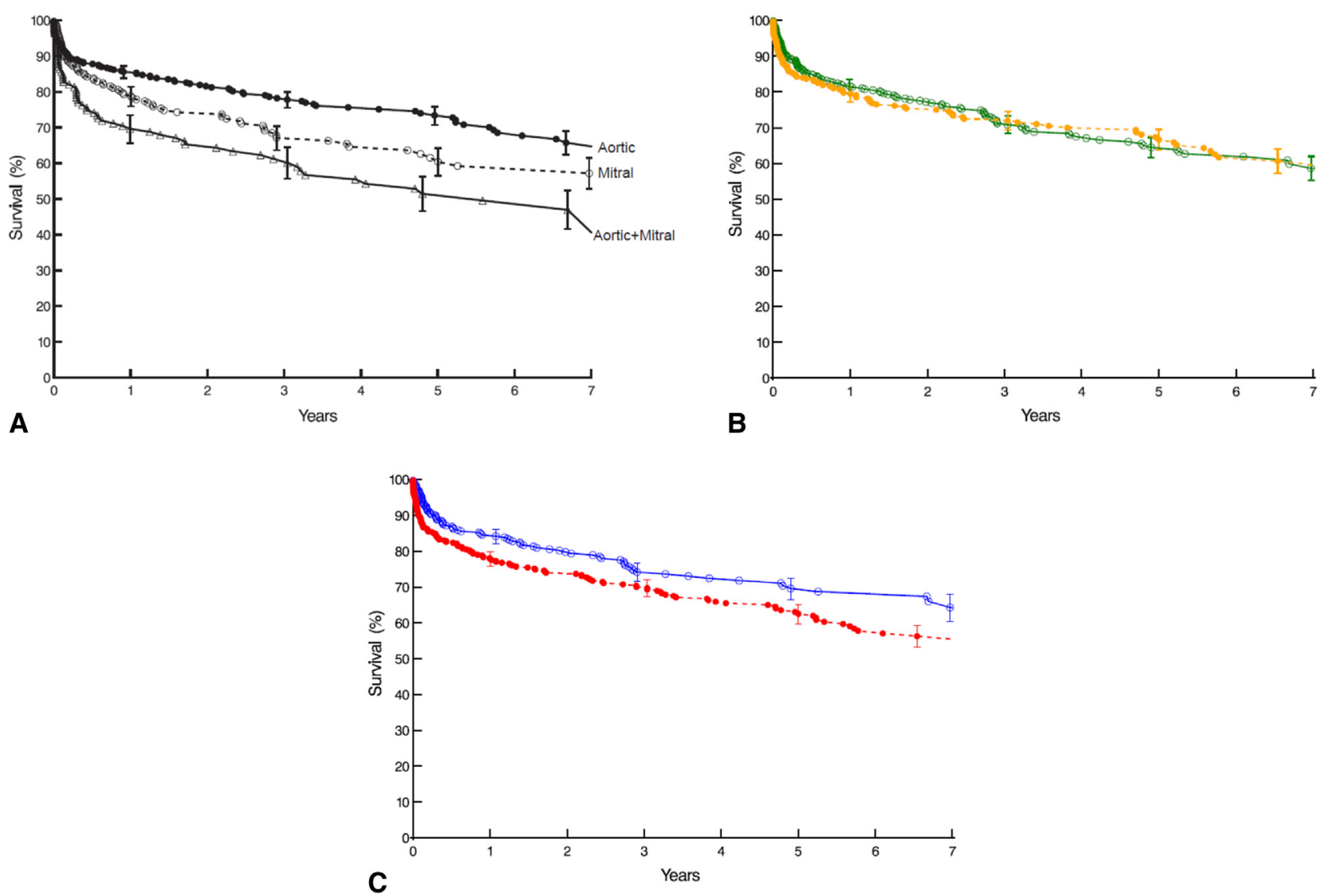

FIGURE E2. Survival after surgery for left-sided infective endocarditis (IE). Each symbol represents a death, and vertical bars represent the $68 \%$ confidence limits, equivalent to \pm 1 standard error. A, Stratified by involved valve. Filled circles indicate aortic valve IE alone; open circles, mitral valve IE alone; and triangles, aortic and mitral valve IE. B, Stratified by native (solid green line and open circles) versus prosthetic (dashed orange line and filled circles) valve endocarditis. C, Invasive (dashed red line and filled circles) versus noninvasive (solid blue line and open circles) disease.
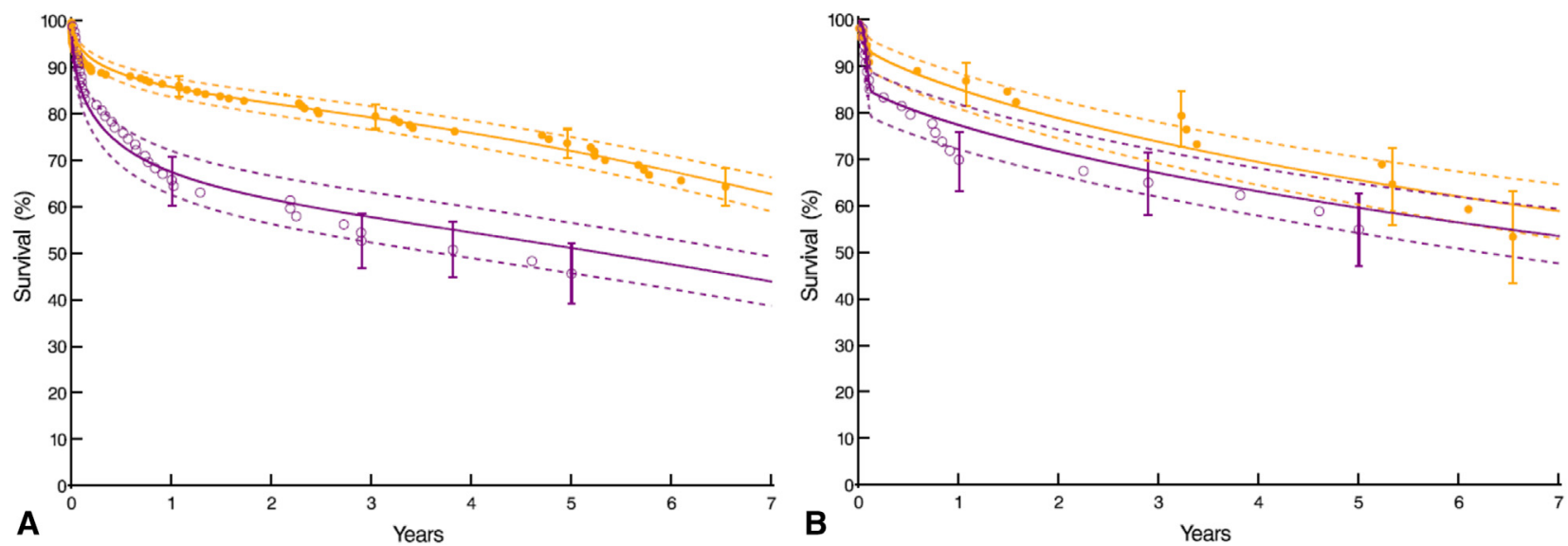

FIGURE E3. Survival after surgery for invasive aortic valve infective endocarditis (IE) versus mitral disease. Each symbol represents a death, and vertical bars represent the $68 \%$ confidence limits, equivalent to \pm 1 standard error. Solid lines indicate parametric estimates enclosed within a $68 \%$ confidence band. Orange solid line and filled circles indicate aortic valve IE; and purple solid line and open circles, mitral valve IE. A, Unadjusted survival. $\mathrm{B}$, Propensity-matched patients. 
TABLE E1. Preoperative patient characteristics associated with invasive isolated mitral valve infective endocarditis (vs invasive isolated aortic disease)

\begin{tabular}{lccc}
\hline \multicolumn{1}{c}{ Factor } & Coefficient \pm SE & $\boldsymbol{P}$ value & Reliability $(\%)^{*}$ \\
\hline NVE & $2.2 \pm 0.34$ & $<.0001$ & 95 \\
Previous stroke & $0.78 \pm 0.33$ & .02 & 30 \\
Preoperative dialysis & $0.88 \pm 0.39$ & .02 & 30 \\
Larger LA volume & $0.044 \pm 0.0078$ & $<.0001$ & 84 \\
Female sex & $1.5 \pm 0.33$ & $<.0001$ & 69 \\
Intercept & $-5.4 \pm 0.59$ & $<.0001$ & - \\
\hline
\end{tabular}

C-statistic $=0.85 . S E$, Standard error; $N V E$, native valve endocarditis; $L A$, left atrial

*Percentage of times factor appeared in 1000 bootstrap models.

TABLE E2. Incremental risk factors for death after surgery for leftsided infective endocarditis

\begin{tabular}{lcc}
\hline \multicolumn{1}{c}{ Factor } & Coefficient \pm SE & $P$ value \\
\hline Early phase & & \\
Older age* & $0.27 \pm 0.14$ & .05 \\
Higher bilirubin $\dagger$ & $0.74 \pm 0.15$ & $<.0001$ \\
Higher blood urea nitrogen $\dagger$ & $0.91 \pm 0.17$ & $<.0001$ \\
Peripheral arterial disease & $1.2 \pm 0.24$ & $<.0001$ \\
Concomitant CABG & $0.72 \pm 0.24$ & .003 \\
MV only group $\ddagger$ & $-0.031 \pm 0.38$ & .9 \\
Combined AV and MV group $\ddagger$ & $0.52 \pm 0.29$ & .08 \\
Invasive disease in AV IE & $0.040 \pm 0.34$ & .9 \\
Invasive disease in MV IE & $0.30 \pm 0.30$ & .3 \\
PVE & $0.33 \pm 0.26$ & .2 \\
Late phase & & \\
Older age* & $0.40 \pm 0.108$ & .0002 \\
Lower hematocrit $\dagger$ & $-1.6 \pm 0.44$ & .003 \\
COPD & $0.59 \pm 0.21$ & .005 \\
Preoperative dialysis & $1.9 \pm 0.21$ & $<.0001$ \\
Left atrial diameter $>6 \mathrm{~cm}$ & $1.14 \pm 0.39$ & .004 \\
Lower cholesterol $§$ & $0.073 \pm 0.024$ & .003 \\
MV affected $\|$ & $0.65 \pm 0.23$ & .005 \\
Invasive disease in aortic IE & $0.081 \pm 0.21$ & .7 \\
Invasive disease in mitral IE & $-0.18 \pm 0.26$ & .5 \\
\hline
\end{tabular}

$S E$, Standard error; $C A B G$, coronary artery bypass grafting; $M V$, mitral valve; $A V$, aortic valve; $I E$, infective endocarditis; $P V E$, prosthetic valve endocarditis; $C O P D$, chronic obstructive pulmonary disease. *Exp(age/50), exponential transformation. $\dagger$ Logarithmic transformation. $\ddagger$ Compared with $\mathrm{AV}$ group. $\S\left(200 /\right.$ cholesterol $^{2}$, inverse squared transformation. ||MV group and combined $\mathrm{AV}$ and $\mathrm{MV}$ group compared with $\mathrm{AV}$ group.
TABLE E3. Clinical and management characteristics of patients treated surgically for left-sided infective endocarditis

\begin{tabular}{|c|c|c|c|}
\hline Characteristic & $\begin{array}{c}\text { AV } \\
(\mathbf{n}=\mathbf{3 9 5})\end{array}$ & $\begin{array}{c}\text { MV } \\
(\mathbf{n}=\mathbf{2 3 8})\end{array}$ & $\begin{array}{c}A V \text { and } M V \\
(n=142)\end{array}$ \\
\hline \multicolumn{4}{|l|}{ Demographic data } \\
\hline Age (y) & $58 \pm 15$ & $57 \pm 14$ & $55 \pm 15$ \\
\hline Female sex & $92(23)$ & $102(43)$ & $38(27)$ \\
\hline \multicolumn{4}{|l|}{ Presentation } \\
\hline NYHA functional class III-IV & $108(27)$ & $76(32)$ & $48(34)$ \\
\hline Emergency or salvage & $18(4.6)$ & $15(6.3)$ & $9(6.4)$ \\
\hline Previous stroke & $120(30)$ & $100(42)$ & $47(33)$ \\
\hline Previous MI & $105(27)$ & $55(23)$ & $29(21)$ \\
\hline Complete heart block or pacer & $35(9.0)$ & $12(5.2)$ & $16(12)$ \\
\hline $\begin{array}{l}\text { Acute or chronic renal disease } \\
\text { requiring DM }\end{array}$ & $43(11)$ & $42(18)$ & $22(16)$ \\
\hline Preoperative length of stay $(\mathrm{d}) *$ & $1.9,5.4,11$ & $1.8,6.6,13$ & $1.9,5.9,13$ \\
\hline \multicolumn{4}{|l|}{ Cardiac morbidity } \\
\hline \multicolumn{4}{|l|}{ Previous cardiac operation } \\
\hline None & $147(37)$ & $134(56)$ & $68(48)$ \\
\hline 1 & $176(45)$ & $70(30)$ & $49(35)$ \\
\hline 2 & $60(15)$ & $23(9.7)$ & $20(14)$ \\
\hline$\geq 3$ & $12(3.0)$ & $10(4.2)$ & $4(2.8)$ \\
\hline \multicolumn{4}{|l|}{$\mathrm{AV}$} \\
\hline Stenosis & $32(8.1)$ & $9(3.8)$ & $14(9.9)$ \\
\hline $\begin{array}{l}\text { Regurgitation grade } 3+/ 4+ \\
\text { MV }\end{array}$ & $214(56)$ & $2(0.96)$ & $68(50)$ \\
\hline Stenosis & $1(0.25)$ & $24(10)$ & $7(5.0)$ \\
\hline Regurgitation grade $3+/ 4+$ & $41(11)$ & $125(55)$ & $56(42)$ \\
\hline \multicolumn{4}{|l|}{ Noncardiac comorbidity } \\
\hline Hypertension & $269(68)$ & $158(67)$ & $82(58)$ \\
\hline Pharmacologically treated DM & $82(21)$ & $65(28)$ & $25(18)$ \\
\hline COPD & $66(17)$ & $33(14)$ & $25(18)$ \\
\hline Peripheral arterial disease & $46(12)$ & $32(14)$ & $14(9.9)$ \\
\hline \multicolumn{4}{|l|}{ Operative management } \\
\hline AV repair & $9(2.3)$ & $4(1.7)$ & $7(4.9)$ \\
\hline \multicolumn{4}{|l|}{ AV replacement } \\
\hline Mechanical & $14(3.5)$ & $0(0)$ & $11(7 / 8)$ \\
\hline Xenograft & $78(20)$ & $10(4.2)$ & $51(36)$ \\
\hline Allograft & $287(73)$ & $2(0.84)$ & $68(48)$ \\
\hline MV repair & $57(14)$ & $67(28)$ & $67(47)$ \\
\hline \multicolumn{4}{|l|}{ MV replacement } \\
\hline Mechanical & $0(0)$ & $29(12)$ & $10(7.0)$ \\
\hline Xenograft & $5(1.3)$ & $142(60)$ & $63(44)$ \\
\hline CPB time (min) & $160 \pm 66$ & $121 \pm 47$ & $193 \pm 79$ \\
\hline Aortic clamp time (min) & $120 \pm 44$ & $91 \pm 39$ & $154 \pm 63$ \\
\hline
\end{tabular}

Data presented as mean \pm standard deviation or $\mathrm{n}(\%)$, unless otherwise noted. $A V$, Aortic valve; $M V$, mitral valve; $N Y H A$, New York Heart Association; $M I$, myocardial infarction; $D M$, diabetes mellitus; $C O P D$, chronic obstructive pulmonary disease; $C P B$, cardiopulmonary bypass. *Data presented as 15 th, 50 th, 85 th percentiles. 